\section{SYNTHETIC ANATOMY.}

By J. E. Chezsman, Baillière, Tindall and Cox. 1936. 42s.

With the publication of Part 13, on the "Eye and ORBIT," we understand that the unique work on Synthetic Anatomy is complete. The publication of previous parts has been rightly heralded by other reviewers as original, remarkable, ingenious, fascinating and useful.

The Part under review fully maintains this high standard, and should prove most valuable to teachers, practitioners, and students of ophthalmology, as well as to those concerned with the study of anatomy. The method of presentation of the orbit and its contained structures is both original and instructive. The relations of the eyeball and of the orbital muscles, vessels, and nerves, are most accurately and clearly shown. Special praise must be given to the successful portrayal of the relations of the orbit to surrounding structures, especially the accessory nasal sinuses.

This Synthetic Anatomy, now available in its completed form, is a genuine contribution to the Art of Pictorial Anatomy. Its deserved popularity among students speaks of its usefulness in the early part of medjcal training. It is, indeed, the best substitute to actual dissection, in existence. We consider it of equal value to practitioners of medicine and surgery, who appreciate the practical value of anatomical knowledge, and who are anxious to retain it with a minimal expenditure of time and effort.

We congratulate Dr. Cheesman on his brilliant achievement. It is novel, it is accurate, and, it is of immense value. We wish it the success it so richly merits.

\section{ARTHRITIS IN WOMEN.}

\section{Br Dr. Fortescue Fox. H. K. I.ewis. 1936. Price $2 / 6$.}

One of the greatest problems in modern medicine is not so much that of sudden, acute illness but rather one of chronic illhealth, its prevention, arrest and cure.
The rheumatic diseases are a typical example of the problem of chronic ill-health and Dr. Fortescue Fox's survey of "Arthritis in Women," with notes and statistics from other countries, merits close study.

It is questionable whether his classification would be generally accepted. The analogy to tuberculosis is noteworthy and the statistical side of the subject is of considerable value.

Dr. Fox's suggestion for setting up "rest-houses" for sufferers from rheumatoid arthritis deserves serious consideration but, at the same time, the term " rest-house" is a bad one and should be replaced by the term "sanatorium." On the continent this word does not necessarily connote an institution for the treatment of tuberculosis. Rather does it imply an active institution where patients can receive constant medical supervision with facilities for every modern method of treatment under the best possible conditions. "Rest-house," on the other hand, fails to convey the idea that the institution is an active one, which is what Dr. Fox wishes to imply.

Coinciding with the inauguration of the Empire Rheumatism Campaign, Dr. Fox's review of "Arthritis in Women" should be accorded serious attention.

\section{ON THE INCIDENCE OF ANESTHETIC COMPLICATIONS AND THEIR RELATION TO BASAL NARCOSIS.}

By C. J. M. Dawkins, M.A., M.D., B.Chir. D.A. Foreword by J. Blomfield, O.B.E., M.D. Middlesex Hospital Press. 1936. pp. 56. Price $3 / 6$.

There is no doubt that the introduction of basal narcosis has, on the whole, proved of benefit to apprehensive humanity.

Unfortunately, as is the case with most medical novelties lauded by the lay Press, basal narcosis has been carried to extreme lengths and for some time past there has been an uncomfortable feeling that the price paid for it was becoming too high. 
The object of Dr. Dawkins' little book is to assess the influence of the new development on post-operative mortality and morbidity. For this purpose an analysis has been made of no less than 16,000 general and local anæsthesias used with and without various types of basal narcosis.

The collection and tabulation of such a vast mass of statistics have obviously entailed an immense amount of work and Dr. Dawkins' conclusions should be read and taken to heart by all engaged in surgery and anæsthesia. It is impossible even to summarize his results here, but several important facts emerge. One is that, as so many previous observers have found, local analgesia, per se, does not diminish pulmonary complications. The chief point that the author makes, however, is that the incidence of these complications is greatly increased by the use of routine and injudicious basal narcosis.

An unbiased survey of this subject has been long overdue and one cannot escape the conclusion that if basal narcosis is to be employed, it must be in the sole charge of a really experienced anæsthetist who has considered the patient and operation from every relevant angle.

A list of 90 references is found at the end of the book.

\section{FOOD AND THE PRINCIPLES OF DIETETICS.}

\section{(Eighth Edition)}

By Dr. Robt. Hutchison and Prof. V. H.

Mottram. Messrs. Edward Arnold \& Co. 1936. Price 21/-.

Although this is the eighth edition of this well-known book we feel sure that there never was a time when it would be not only more welcome but also more useful. Since the last edition the world has become diet or food conscious, and hence there is an. urgent need that reliable and sound information on the part which food plays in health and disease should be available. The scientific, and unfortunately also unscientific, work which has been done during the last fifty years on the general subject of nutrition, on the analysis of different foods, on the changes which these undergo during the process of cooking or other treatment, and on their effects on the physiological and pathological processes is enormous. In this volume Dr. Hutchison and his collaborator Prof. Mottram have brought together the fruit of this labour, and what is equally if not more important, they have submitted the available information to a scientific and clinical scrutiny so that a most sound, dependable and, it may also be mentioned, readable work is the result. There are many illustrations and tables of analyses and copious references to original sources throughout the text, and a very full index which renders the work in addition a valuable book of ready reference.

\section{A SYSTEM OF CLINICAL MEDICINE.}

\section{(Tenth Edition.)}

Edited by Agnes Savill, M.D. and E. C. WARNER, M.D. Messrs. Edward Arnold \& Co. 1936. Price 28/-.

Any book which has passed through ten editions has demonstrated conclusively that it supplies a demand and that this has been the case with Savill's System of Clinical Medicine is not cause for surprise. Indeed, it is astonishing that it has no competitors for the plan of the book is an admirable method of arousing the student's interest in his subject and thus of imparting knowledge. Most text-books confine themselves either to methods of physical diagnosis or to a more or less academic discussion of the different diseases grouped according to ætiology or organ or part of body attacked. In Savill's Medicine, however, the introduction is by symptom and from this the student is conducted through the necessary examination to a consideration of the possible diseased conditions, the ætiology, life history and treatment being finally discussed. It is in this way, we are convinced, that the facts are most firmly impressed on the memory of the reader.

Each succeeding edition has been more comprehensive than its predecessor and in this, the tenth, in which Dr. Agnes Savill (the widow of the original author) has the assistance as co-editor of Dr. E. C. Warner and the help of a group of well-known 